\title{
Seroprevalence of Mycobacterium avium subsp. paratuberculosis in Dairy Cattle in Khartoum State, Sudan
}

Wisal A. Elmagzoub ${ }^{1,2}$, Nabawia M. Adam ${ }^{3,+}$, Sanaa M. Idris ${ }^{1,4,+}$, Mohamed E. Mukhtar ${ }^{5}$, Sanaa A. Abdelaziz ${ }^{3}$, Julius B. Okuni ${ }^{6}\left(\mathbb{D}\right.$, Lonzy Ojok ${ }^{6,7}$, Ahmed Abd El Wahed ${ }^{8, *(D)}$, ElSagad Eltayeb ${ }^{9}$ D, Ahmed A. Gameel ${ }^{4}$ and Kamal H. Eltom ${ }^{1, *(\mathbb{C}}$

1 Unit of Animal Health and Safety of Animal Products, Institute for Studies and Promotion of Animal Exports, University of Khartoum, Shambat 13314, Khartoum North, Sudan; wisalelmagzoub@gmail.com (W.A.E.); sanaaidris15@gmail.com (S.M.I.)

2 Department of Biology and Biotechnology, College of Applied and Industrial Sciences, University of Bahri, Alkadaro 13316, Khartoum North, Sudan

3 Department of Microbiology, Faculty of Veterinary Medicine, University of Khartoum, Shambat 13314, Khartoum North, Sudan; nabawiavet02011@gmail.com (N.M.A.); sabdelaziz262@gmail.com (S.A.A.)

4 Department of Pathology, Faculty of Veterinary Medicine, University of Khartoum, Shambat 13314, Khartoum North, Sudan; aargameel@hotmail.com

5 Department of Agricultural Extension and Rural Development, Faculty of Agriculture, University of Khartoum, Shambat 13314, Khartoum North, Sudan; elgadidwas@yahoo.com

6 College of Veterinary Medicine, Animal Resources and Biosecurity (COVAB), Makerere University, P.O. Box 7062, Kampala, Uganda; jbokuni@gmail.com (J.B.O.); lonzyo@yahoo.com (L.O.)

7 Department of Pathology, Faculty of Medicine, Gulu University, P.O. Box 166, Gulu, Uganda

8 Institute of Animal Hygiene and Veterinary Public Health, Faculty of Veterinary Medicine, University of Leipzig, an den Tierkliniken 43, D-04103 Leipzig, Germany

9 Faculty of Medicine, Al Neelain University/Ibn Sina Specialised Hospital, Alamarat, Street 17-21, 12217 Khartoum, Sudan; sagadgady@yahoo.com

* Correspondence: ahmed.abd_el_wahed@uni-Leipzig.de (A.A.E.W.); kamal@uofk.edu (K.H.E.); Tel.: +49-3419-738-153 (A.A.E.W.); +249-9102-899-16 (K.H.E.)

+ Equally contributed.

Received: 13 November 2020; Accepted: 16 December 2020; Published: 21 December 2020

\begin{abstract}
Paratuberculosis, caused by Mycobacterium avium subspecies paratuberculosis (MAP), is a chronic wasting disease mainly of domestic and wild ruminants. It occurs worldwide, causing significant economic losses through decreased productivity, low fertility, increased cull rates and mortality. It is listed by the OIE (World Organization for Animal Health) as a disease of concern to trade in animals. Prevalence of this disease can be studied by detecting anti-MAP antibodies by Enzyme linked immunosorbent Assay (ELISA). The aim of this study was to investigate the current prevalence of MAP infection in cattle in Khartoum State. The overall apparent prevalence of MAP infection was found to be $6.3 \%$ and $18.9 \%$ at animal and herd levels, respectively. All seropositive animals were cross-bred females of good body condition; most of them $(>90 \%)$ were $>3$ years old and $>50 \%$ were from medium-sized herds in Omdurman. No significant association $(p>0.05)$ was found between seropositivity and animal herd size. The prevalence of MAP infection in Khartoum State is still low to medium compared to other parts of the world, but it is comparable to those reported from other African countries. Further studies with the view of designing nationwide surveys in domestic ruminants and camels in other states of the country are needed for establishing control programmes.
\end{abstract}

Keywords: Mycobacterium avium paratuberculosis; seroprevalence; cattle 


\section{Introduction}

Paratuberculosis (PTB), also known as Johne's disease, is a chronic enteritis caused by Mycobacterium avium subsp. paratuberculosis (MAP) affecting ruminants and wild mammals worldwide [1,2]. It is listed by the OIE (World Organization for Animal Health) as a disease of concern to trade in animals. The disease affects animals of all ages, manifesting as different clinical stages [3-5], causing decreased productivity, low fertility and increased susceptibility to infections [6]. Moreover, MAP is suspected to be involved in the aetiology of Crohn's disease, a chronic diarrhoeal inflammatory bowel disease of humans, which shares some features with PTB [3,7]. Due to the serious economic impact of PTB on livestock production, control of MAP is very important wherever it occurs. This requires early detection of infected livestock and sufficient information of the rate of infection and associated risk factors in the population.

Diagnosis of PTB is based on one or more of the following: isolation of MAP or detection of its DNA in tissues or faeces, detection of MAP antibodies and culture to isolate the organism. The suitability and sensitivity of the tests depend on the clinical stage of the disease [8,9]. Silent infection can be detected only by histopathology or MAP tissue culture, which takes a long time [10,11]. Enzyme-Linked Immuno-Sorbent Assay (ELISA) is a favourable and commonly used serological test to detect MAP antibodies in serum and milk in the subclinical stage of MAP infection and afterwards [3,10]. ELISA's sensitivity may reach a maximum of 50\% [8] and its specificity can be improved through pre-treatment of samples with Mycobacterium phlei to absorb non-specific antibodies [12] and minimize possible false positives.

Knowledge of the global distribution of PTB is important for establishing control programmes. The prevalence of PTB has been reported from different countries, mainly for bovine PTB. Herd-level prevalence of up to $75.8 \%$ was reported in the Caribbean and Latin America [13], of $>50 \%$ in Europe and North America [14] and of 20.35-41.7\% in Asia [15,16]. Animal-level prevalence ranging from $2.31 \%$ to $29.8 \%$ was also reported in Asia [15-18]. In Africa, reports on MAP infections in animals are rather scant. Available published data show herd prevalence of $45.2 \%$ and $13 \%$ in Egypt and Uganda, respectively [19,20], and animal-level prevalence of 9\% in Uganda [20] and 5.26\% in Tanzania [21]. Although PTB was first diagnosed in cattle and goats in Sudan more than 50 years ago [22,23], there has been little research and few reports about its incidence and prevalence. The first report on bovine PTB in the Sudan was from Khartoum, with 53\% prevalence, based mainly on the diagnosis of the clinical disease [23]. A more recent study on bovine PTB in Khartoum State by Mohammed et al. in 2010 revealed $66.7 \%$ and $10.2 \%$ prevalence at the herd and animal levels, respectively [24], but it was limited since it involved only a few farms. The present study aimed at evaluating the current situation of PTB in dairy farms in Khartoum State by increasing the number of herds in a wider area.

\section{Materials and Methods}

\subsection{Ethical Statement}

Ethics approval for the study was waived by the Research Board of the Faculty of Veterinary Medicine and the Scientific Committee of the Institute for Studies and Promotion of Animal Exports, University of Khartoum. The samples were taken as part of routine diagnosis by authorized veterinarians according to the national veterinary and animal welfare regulations.

\subsection{Study Population}

Animals included in this study were local (Butana/Kenana) and cross-bred (local $\times$ Friesian) cattle of both sexes and different ages selected through stratified random sampling from different dairy herds in three major areas in Khartoum State (Figure 1): 11 herds in Khartoum, 17 in Khartoum North and 9 in Omdurman, based on cooperation from animal owners/herders. Most of the animals were of good body condition. 


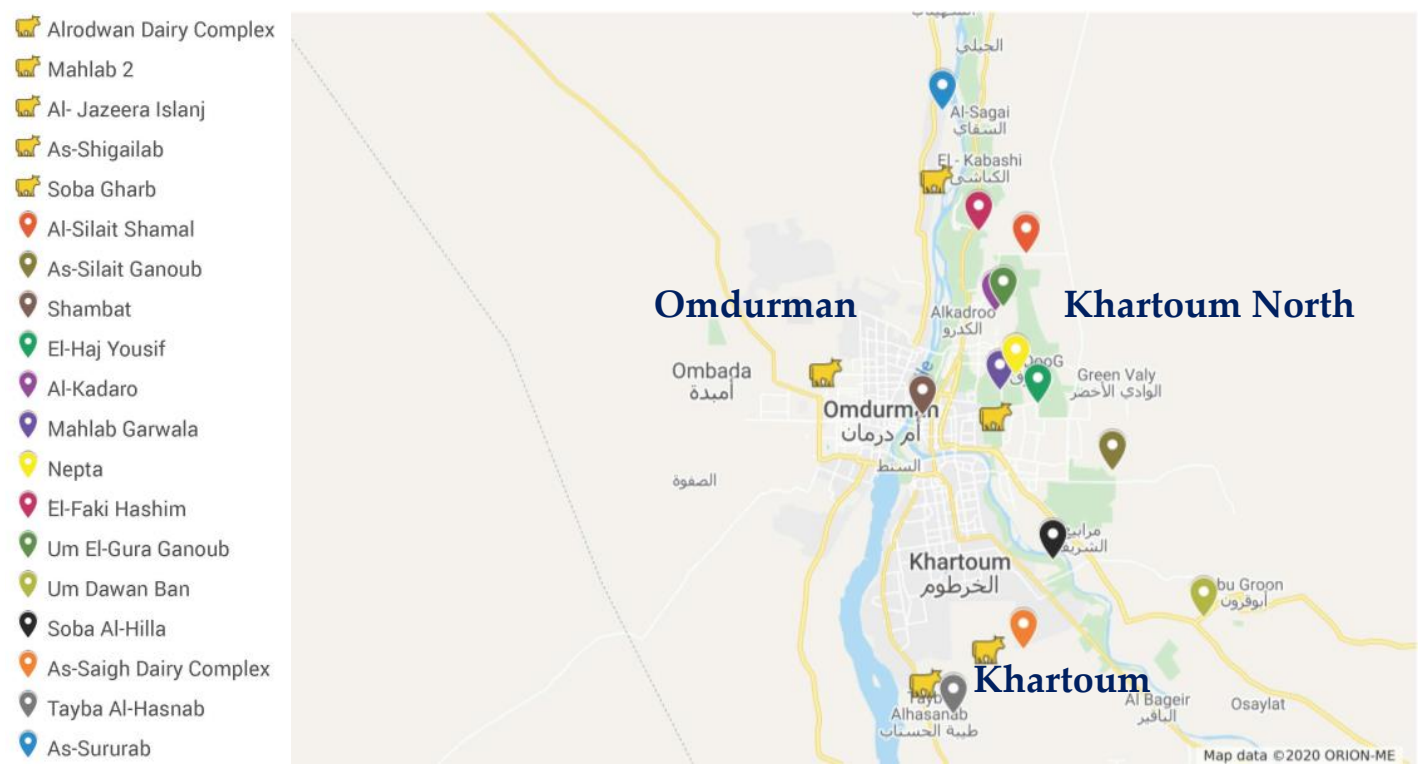

Figure 1. Locations $(\mathrm{N}=19)$ of 37 dairy farms sampled for the seroprevalence of Mycobacterium avium subsp. paratuberculosis (MAP) in Khartoum State. Locations with the cow symbol are those with MAP +ve herds. The map was created from Google Maps®using Google's account of Kamal H. Eltom.

\subsection{Enzyme Linked Immuno Sorbent Assay (ELISA) Procedure}

The obtained sera were tested for anti-MAP antibodies using the IDEXX Paratuberculosis Screening $\mathrm{Ab}$ Test (IDEXX laboratories Inc. Westbrook, USA) according to the manufacturer's instructions. In brief, the test samples and the provided controls were diluted 1:20 with the provided buffer containing Mycobacterium phlei and left (as a pre-incubation) for $35 \mathrm{~min}$. The plate coated with MAP antigen was incubated for $45 \mathrm{~min}$ with $100 \mu \mathrm{L}$ of the diluted test samples and controls. The plate was then washed thrice, $100 \mu \mathrm{L}$ of conjugate was added, plates were left for $30 \mathrm{~min}$ and washed as before; $100 \mu \mathrm{L}$ of TMB solution was added and left for $10 \mathrm{~min}$, followed by $100 \mu \mathrm{L}$ of stop solution. The optical density of the plates was read at $450 \mathrm{~nm}$ in a plate reader. According to manufacturer's guidelines, the results were validated and then interpreted as positive or negative.

\subsection{Statistical Analysis}

The results were analysed using SAS software version 9 (SAS Institute Inc., Cary, NC, USA). The data obtained were compared using the Pearson chi-squared test.

\section{Results and Discussion}

In this study, antibodies against MAP were demonstrated by ELISA in 7 out of 37 dairy herds tested in Khartoum State with an overall herd prevalence of $18.9 \%$ and animal-level prevalence of $6.3 \%$. Three of the positive herds were in Omdurman, which also had the highest prevalence at the animal level (33.3\%); two positive herds were found in each of the other two localities. A summary of the results is presented in Table 1. As the maximum sensitivity of ELISA is about $50 \%$, the true estimation of seroprevalence could be higher than the obtained results. However, ELISA-positive animals may or may not be MAP shedders; antibodies could be produced before shedding started or years after [5], but precautions should be taken to minimize the transmission of infection within the herd.

All seropositive animals were cross-bred females of good body condition; most ( $>90 \%)$ of them were above three years old and $>50 \%$ were from a medium-size herd (50-100 heads). The chronic nature of MAP infection and the long incubation period render the infected animals apparently healthy for years before showing overt symptoms of the disease [25], which may explain our findings. The numbers of local cattle in the farms investigated was small, and none of the tested animals was 
seropositive. Local breeds are poor milkers compared to exotic breeds or their crosses, and, therefore, limited numbers of selected cows were included. However, PTB surveys should also include pastoral local herds in Sudan. It is interesting that the chi-squared test showed no significant association between these descriptive animal data and serostatus (Table 2).

Table 1. Prevalence of MAP antibodies in dairy cattle in Khartoum State.

\begin{tabular}{|c|c|c|c|c|c|c|}
\hline \multirow{3}{*}{ Area } & \multicolumn{3}{|c|}{ Animal Level } & \multicolumn{3}{|c|}{ Herd Level } \\
\hline & \multirow{2}{*}{ No. Tested } & \multicolumn{2}{|c|}{ Positive } & \multirow{2}{*}{ No. Tested } & \multicolumn{2}{|c|}{ Positive } \\
\hline & & No. & $\%$ & & No. & $\%$ \\
\hline Khartoum & $51 *$ & 2 & 3.9 & 11 & 2 & 18.2 \\
\hline $\begin{array}{l}\text { Khartoum } \\
\text { North }\end{array}$ & 78 & 4 & 5.1 & 15 & 2 & 13.3 \\
\hline Omdurman & 45 & 5 & 11.1 & 9 & 3 & 22.2 \\
\hline Total & 175 & 11 & 6.3 & 37 & 7 & 18.9 \\
\hline
\end{tabular}

Table 2. Chi-squared test results for associations between cattle age, body condition, herd size, sex and prevalence of MAP antibodies in Khartoum State.

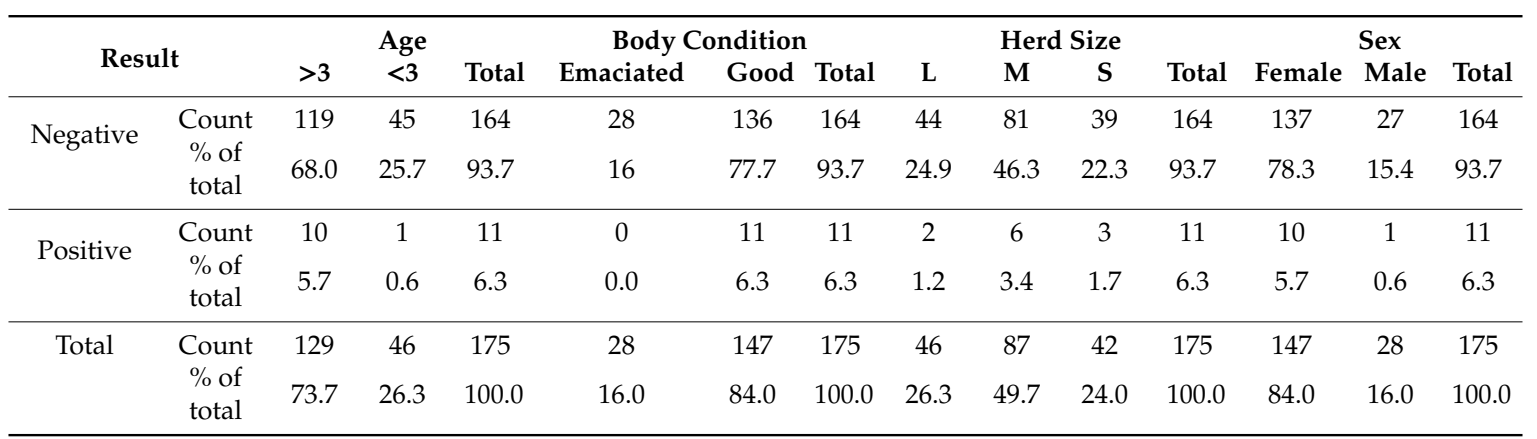

The chi-squared test results showed that the association between cattle age and the prevalence of MAP antibodies was not significant (chi-squared value $=1.9, p>0.05$ ); similarly, the association between the cattle body condition and the prevalence of such antibodies was insignificant (chi-squared value $=2.2, p>0.05$ ). Neither sex nor the herd size was significantly associated with the prevalence of MAP antibodies (chi-squared value $=0.5, p>0.05$ ) and (chi-squared value $=0.38, p>0.05)$, respectively. L (Large herd), M (Medium herd) and S (Small herd).

The only reliable report from Sudan on the seroprevalence of bovine PTB available to compare the current results with is that of Mohammed et al. [24], who reported $66.7 \%$ and $10.2 \%$ prevalence at the herd and individual animal levels, respectively, in Khartoum State. These rates are higher than those reported here, but our study is more representative due to involving greater number of herds distributed over a wider area of Khartoum State (Figure 1). Moreover, they involved clinical cases; when these are excluded, the apparently healthy animals would reveal a comparable animal-level prevalence (6.9\%). Contrary to the current results, they reported the lowest seropositivity in Omdurman. Possible explanations for this increase in seropositivity of herds in Omdurman could be the establishment of infection through time because of close proximity of dairy farms and stability of locations of many dairy compounds for the last three decades, while in Khartoum and Khartoum North, the dairy compounds' locations had been changed due to the encroachment of urban areas.

It is obvious that PTB in Sudan is poorly documented. Similarly, reports from other African countries on MAP infections in animals are rather scant [26]. However, the prevalence rates, at herd or individual animal levels, reported from Egypt [19], Uganda [20] and Tanzania [21] are reasonably comparable with the present results. Global prevalence of PTB is high, and the disease is well documented in many developed countries, where it causes tremendous economic losses. The prevalence rates of PTB obtained in this study seem to be low compared to those mentioned globally [13,15-18]. 
Generally, variation between the results obtained by various authors may be influenced by the stage of infection, animal age, shedding level of the organism, lactation, antibody concentration and varying sensitivity among different ELISAs $[5,8,25,27]$. These should be considered when comparing results on PTB prevalence.

It has been stated that ELISA is more precise in determining herd-level prevalence [8]; however, the combination of ELISA with culture or molecular assays for the screening of MAP infection would be more reliable in investigating both animal- and herd-level prevalence.

\section{Conclusions}

The present study confirms that MAP infection occurs in dairy cattle in Khartoum State at a similar prevalence to other African countries. However, studies that are more detailed are needed to establish a better view on the prevalence, which will allow the establishment of control programmes. This will allow a more optimal and sustainable production system for Sudan and Africa, enabling better food supply for the people.

Author Contributions: Conceptualization, S.A.A., M.E.M. and K.H.E.; methodology, N.M.A., W.A.E. and S.M.I.; validation, J.B.O., L.O. and E.E.; formal analysis, M.E.M.; investigation, S.M.I.; resources, A.A.E.W.; data curation, W.A.E.; writing—original draft preparation, W.A.E.; writing-review and editing, A.A.G.; visualization, E.E.; supervision, K.H.E.; project administration, K.H.E.; funding acquisition, A.A.E.W. All authors have read and agreed to the published version of the manuscript.

Funding: This research was funded by the German Research Foundation (DFG), grant number 404935781.

Acknowledgments: Mojahed Haroun provided assistance during sample collection; Islam Kamaleldin, Nehal Mohamed and Eiman Hassab Elrasoul of Detasi Company provided the equipment facility.

Conflicts of Interest: The authors declare no conflict of interest. The funders had no role in the design of the study; in the collection, analyses, or interpretation of data; in the writing of the manuscript; or in the decision to publish the results.

\section{References}

1. Fawzy, A.; Zschöck, M.; Ewers, C.; Eisenberg, T. Genotyping methods and molecular epidemiology of Mycobacterium avium subsp. paratuberculosis (MAP). Int. J. Vet. Sci. Med. 2018, 6, 258-264. [CrossRef] [PubMed]

2. Rathnaiah, G.; Zinniel, D.K.; Bannantine, J.P.; Stabel, J.R.; Gröhn, Y.T.; Collins, M.T.; Barletta, R.G. Pathogenesis, Molecular Genetics, and Genomics of Mycobacterium avium subsp. paratuberculosis, the Etiologic Agent of Johne's Disease. Front. Vet. Sci. 2017, 4, 187. [CrossRef] [PubMed]

3. Garvey, M. Mycobacterium avium subspecies paratuberculosis: A possible causative agent in human morbidity and risk to public health safety. Open Vet. J. 2018, 8, 172-181. [CrossRef] [PubMed]

4. Gautam, M.; Ridler, A.; Wilson, P.R.; Heuer, C. Control of clinical paratuberculosis in New Zealand pastoral livestock. N. Z. Vet. J. 2017, 66, 1-8. [CrossRef] [PubMed]

5. Nielsen, S.S. Immune-based diagnosis of paratuberculosis. In Paratuberculosis, Organism, Disease and Control; Behr, M.A., Collins, D.M., Eds.; CABI Head Office: Wallingford, Oxfordshire, UK, 2010; pp. 284-291.

6. Garcia, A.B.; Shalloo, L. Invited review: The economic impact and control of paratuberculosis in cattle. J. Dairy Sci. 2015, 98, 5019-5039. [CrossRef]

7. Behr, M.A. Paratuberculosis and Crohn's disease. In Paratuberculosis, Organism, Disease and Control; Behr, M.A., Collins, D.M., Eds.; CABI Head Office: Wallingford, Oxfordshire, UK, 2010; pp. 40-50.

8. Barkema, H.W.; Hesselink, J.W.; McKenna, S.; Benedictus, G.; Groenendaal, H. Global prevalence and economics of infection with Mycobacterium avium subsp. paratuberculosis in ruminants. In Paratuberculosis: Organism, Disease, Control; CABI Publishing: Wallingford, Oxfordshire, UK, 2010; pp. 10-21.

9. Whittington, R.J.; Begg, D.J.; De Silva, K.; Purdie, A.C.; Dhand, N.K.; Plain, K.M. Case definition terminology for paratuberculosis (Johne's disease). BMC Vet. Res. 2017, 13, 1-13. [CrossRef]

10. Radostits, O.; Gay, C.; Hinchcliff, K.; Constable, P. Veterinary Medicine, 10th ed.; Saunders: Philadelphia, PA, USA, 2007. 
11. Whittington, R.J.; Marsh, I.B.; Saunders, V.; Grant, I.R.; Juste, R.; Sevilla, I.A.; Manning, E.J.; Whitlock, R.H. Culture phenotypes of genomically and geographically diverse Mycobacterium avium subsp. paratuberculosis isolates from different hosts. J. Clin. Microbiol. 2011, 49, 1822-1830. [CrossRef]

12. Bannantine, J.P.; Paustian, M.L.; Kapur, V.; Eda, S. Proteome and antigen of Mycobacterium avium subsp. paratuberculosis. In Paratuberculosis Organism, Disease, Control; Behr, M.A., Collins, D.M., Eds.; CABI Head Office: Wallingford, Oxfordshire, UK, 2010; pp. 94-109.

13. Fernández-Silva, J.; Correa-Valencia, N.M.; Ramírez, N.F. Systematic review of the prevalence of paratuberculosis in cattle, sheep, and goats in Latin America and the Caribbean. Trop. Anim. Heal. Prod. 2014, 46, 1321-1340. [CrossRef]

14. Imada, J.; Kelton, F.D.; Barkema, H.W. Epidemiology, Global Prevalence and Economics of the Infection. In Paratuberculosis, Organism, Disease, Control, 2nd ed.; Behr, M.A., Stevenson, K., Kapur, V., Eds.; CABI Publishing: Wallingford, Oxfordshire, UK, 2020; pp. 1-13.

15. Lee, K.W.; Jung, B.Y. Seroprevalence of Mycobacterium avium subspecies paratuberculosis in cattle in Korea. Vet. Rec. 2009, 165, 661-662. [CrossRef]

16. Sun, W.-W.; Lv, W.-F.; Cong, W.; Meng, Q.-F.; Wang, C.-F.; Shan, X.-F.; Qian, A.-D. Mycobacterium avium subspecies paratuberculosis and Bovine Leukemia Virus Seroprevalence and Associated Risk Factors in Commercial Dairy and Beef Cattle in Northern and Northeastern China. BioMed Res. Int. 2015, 2015, 1-7. [CrossRef]

17. Gurung, R.B.; Begg, D.J.; Whittington, R.J. A national serosurvey to determine the prevalence of paratuberculosis in cattle in Bhutan following detection of clinical cases. Vet. Med. Sci. 2018, 4, 288-295. [CrossRef] [PubMed]

18. Singh, S.V.; Singh, A.V.; Singh, R.; Sharma, S.; Shukla, N.; Misra, S.; Singh, P.; Sohal, J.S.; Kumar, H.; Patil, P.K.; et al. Sero-prevalence of Bovine Johne's disease in buffaloes and cattle population of North India using indigenous ELISA kit based on native Mycobacterium avium subspecies paratuberculosis 'Bison type' genotype of goat origin. Comp. Immunol. Microbiol. Infect. Dis. 2008, 31, 419-433. [CrossRef] [PubMed]

19. Fawzy, A.; Prince, A.; Hassan, A.A.; Fayed, A.; Zschöck, M.; Naga, M.; Omar, M.; Salem, M.; El-Sayed, A. Epidemiological studies on Johne's disease in ruminants and Crohn's disease in humans in Egypt. Int. J. Vet. Sci. Med. 2013, 1, 79-86. [CrossRef]

20. Okuni, J.B.; Loukopoulos, P.; Reinacher, M.; Ojok, L. Seroprevalence of Mycobacterium avium subspecies paratuberculosis Antibodies in Cattle from Wakiso, Mpigi and Luwero Districts in Uganda. Int. J. Anim. Vet. Adv. 2011, 3, 156-160.

21. Mpenda, F.N.; Buza, J. Seroprevalence of bovine paratuberculosis in Arusha, Northern Tanzania. Am. J. Res. Comm. 2014, 2, 97-104.

22. Chaudhary, A.Q.; Fawi, M.T.; Obeid, H.M. Johne's disease in goats in the Sudan. Vet. Rec. 1964, 76, $246-247$.

23. Fawi, M.T.; Obeid, H.M. A note on Johne's disease among cattle in the Sudan. Bull. Epiz. Dis. Afr. 1964, $12,437$.

24. Mohammed, K.B.; El-Eragi, A.; Zakia, A.M. Seroprevalence of Bovine Paratuberculosis Specific Antibodies in Khartoum and Al-Jazeera States, Sudan. J. Anim. Vet. Adv. 2010, 9, 2098-2101. [CrossRef]

25. Mortier, R.A.; Barkema, H.W.; De Buck, J. Susceptibility to and diagnosis of Mycobacterium avium subspecies paratuberculosis infection in dairy calves: A review. Prev. Vet. Med. 2015, 121, 189-198. [CrossRef]

26. Okuni, J.B.; Hansen, S.; Eltom, K.H.; Eltayeb, E.; Amanzada, A.; Omega, J.A.; Czerny, C.-P.; El Wahed, A.A.; Ojok, L. Paratuberculosis: A Potential Zoonosis and a Neglected Disease in Africa. Microorganisms 2020, 8,1007 . [CrossRef]

27. Nielsen, S.S.; Enevoldsen, C.; Gröhn, Y.T. The Mycobacterium avium subsp. paratuberculosis ELISA response by parity and stage of lactation. Prev. Vet. Med. 2002, 54, 1-10. [CrossRef]

Publisher's Note: MDPI stays neutral with regard to jurisdictional claims in published maps and institutional affiliations. 